\title{
Novel Fluorescent Derivative of Praziquantel Interaction with Clonorchis sinensis Cercariae
}

Yunzhi Xie, Lvyin Zheng, Wei Liu, Yongquan Wu, Xun Li, Yibao Li* and Xiaolin Fan*

Key Laboratory of Organo-pharmaceutical Chemistry, Gannan Normal University, Ganzhou 341000, P. R. China

\begin{abstract}
Clonorchiasis is a common infection of dogs and other fish-eating carnivores (reservoir final hosts). Praziquantel is the only medicine, which has been recommended by WHO for treatment of clonorchiasis. To investigate the interaction between praziquantel and Clonorchiasis sinensis cercariae, two praziquantel derivatives (PZQ-2 and PZQ-3) and one praziquantel fluorescent derivative (PZQ-5) were have been synthesized and characterized by nuclear magnetic resonance spectroscopy (NMR) and MS spectra. Confocal fluorescence microscopy revealed that $P Z Q-5$ is mainly located at cercarial tegument, which leads to the death of cercariae with the time increasing.
\end{abstract}

Keywords: Clonorchiasis; Cholangiocarcinoma; Parasitology; $C$. sinensiscercaria

\section{Introduction}

Clonorchiasis caused by Clonorchis sinensis is a fish-borne trematode infection, which is endemic in China, Korea, Japan, and other Southeast Asian countries, with approximately 35 million people being infected globally, of whom approximately 13 million were in China [1]. Epidemiologic and experimental studies have revealed that C. sinensis infections can induce biliary epithelial hyperplasia, periductal fibrosis and cystic changes in the ducts, and promote the development of cholangiocarcinoma [2,3]. Due to a high correlation interaction between clonorchiasis and cholangiocarcinoma, C. sinensis was classified as a class I carcinogen at the meeting for the International Agency for Research on Cancer (IARC) in 2009 [4].

Praziquantel is the only medicine recommended by WHO for treatment of clonorchiasis. It is effective, safe and low-cost. WHO recommends carrying out community diagnosis at the district level, and implementing preventive chemotherapy with praziquantel [5].

The cercarial stage of the $C$. sinensis life-cycle is the important infectious stage. The cercarial stage is also the most fragile stage in the life cycle of $C$. sinensis. However, few papers focus on mechanism of praziquantel interaction with $C$. sinensis cercaria. In our intention paper, we will use fluorescence imaging technology to elucidate the preliminary interaction between praziquantel derivatives and $C$. sinensis cercariae.

Fluorescence imaging has been used as a powerful tool in the study of medicine and bioscience, including parasitology [6-8], especially in studying the interaction between drugs and parasites in vitro and in vivo [9]. Because the abounding of fluorescent probes promoted the development of fluorescent imagingtechnology. Currently, the available fluorescent dyes have been [10-16]: 1) organic fluorescent dyes, 2) phosphorescent metal complexes [12], 3) quantum dots [13], 4) fluorescent protein [14-15], 5) up- converting rare-earth nanophosphors [16]. Charlemagne Gnoula et al. [6] used 5(6)-carboxyfluorescein diacetate to label nematodes. The result has shown that only death nematodes could be labeled. Devon B. Keeney et al. [7] examined the utility of fluorescent fatty acid analog dyes for labeling larval trematodes to use in experimental infections. The 4, 5-diaminofluorescein-2 diacetate (DAF-2 DA) was used by Andrea B. Kohn et al. [17] to detect NO in living schistosomes. These reports indicated fluorescence imaging technology is suitable for investigated interaction between drug and $C$. sinensis cercariae.

The mainly fluorophore of organic fluorescent dyes are fluorescein, naphthalimide, acridine, rhodamine, coumarins, etc. N-hexanoic acid-4-morpholin-1, 8-naphthalimide (compound 4) is a kind of good candidate of fluorescent probes with large "push-pull" electronic system, good light stability and chemical stability. Its fluorescence emission wavelength is moderate $(\approx 520 \mathrm{~nm})$, the fluorescence quantum yield is relatively high, and the stokes shift is larger.

Herein, novel derivatives of praziquantel (Scheme 1, PZQ-2 and PZQ-3) were synthesized by means of nitration and reduction reaction. To investigate the interaction between drug and C. sinensis cercariae, a novel fluorescent compound of PZQ-5 was further synthesized by coupling N-hexanoic acid-4-morpholin-1, 8-naphthalimide
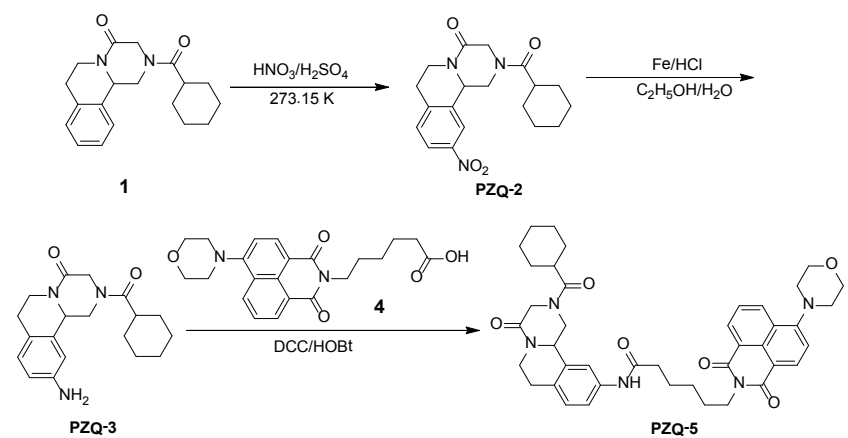

Scheme 1: Synthetic routines of PZQ-5.

*Corresponding authors: Yibao Li, Key Laboratory of Organo-pharmaceutical Chemistry, Gannan Normal University, Ganzhou 341000, P. R. China, Tel/Fax:+86 (0)797 8393536; E-mail: liyb@gnnu.cn

Xiaolin Fan, Key Laboratory of Organo-pharmaceutical Chemistry, Gannan Normal University, Ganzhou 341000, P. R. China, Tel/Fax:+86 (0)797 8393536; E-mail: fanxl2013@gnnu.cn

Received July 30, 2014; Accepted September 15, 2014; Published September 17, 2014

Citation: Xie Y, Zheng L, Liu W, Wu Y, Li X, et al. (2014) Novel Fluorescent Derivative of Praziquantel Interaction with Clonorchis sinensis Cercariae. Med chem 4: 697-700. doi:10.4172/2161-0444.1000214

Copyright: @ 2014 Xie Y, et al. This is an open-access article distributed under the terms of the Creative Commons Attribution License, which permits unrestricted use, distribution, and reproduction in any medium, provided the original author and source are credited. 
(compound 4, Scheme 1) to praziquantel derivative PZQ-3. The cell imaging have been further investigated.

\section{Experimental Section}

\section{Materials and instrumentations}

All starting materials (reagents and solvents) were obtained from commercial supplies and used as received. Praziquantel was purchased from Zhejiang Top Medicine Co., Ltd., (China). The KB cell lines were provided by Institute of Biochemistry and Cell Biology (China). Infected Oncomelania hupensis snails were supplied by Hunan Institute of Parasitic Diseases (WHO collaborating center for Schistosomiasis control in lakes).

${ }^{1} \mathrm{HNMR}$ and ${ }^{13} \mathrm{CNMR}$ spectra were recorded on a Mercuryplus spectrometer at $400 \mathrm{MHz}$ and $100 \mathrm{MHz}$, respectively. Electrospray ionization mass spectra (ESI-MS) were measured on a Bruker APEX II FT-ICRMS 4.7T system. UV-visible spectra were recorded on a Shimadzu UV-2550 spectrometer. Fluorescence spectra were measured on an Edinburgh LFS920 fluorescence spectrophotometer. Fourier transform infrared (FT-IR) spectra were measured using a Nicolet Nexus 470 spectrometer with $\mathrm{KBr}$ pellet. Fluorescence imaging experiments were performed on an OLYMPUS FV1000 IX81 confocal fluorescence microscope equipped with a $40 \mathrm{x}$ oil-immersion objective lens, excitation at $405 \mathrm{~nm}$ was carried out with a semiconductor laser and emission was collected at 480 to $580 \mathrm{~nm}$. MTT assay was measured by means of a Tecan Infinite M200 monochromator-based multifunction microplate reader.

\section{Synthesis}

Synthesis of PZQ-2: PZQ-2 was synthesized as described previously $[18,19] .1 \mathrm{H} \mathrm{NMR}(400 \mathrm{MHz}, \mathrm{CDCl} 3), \delta(\mathrm{ppm}): 8.21(\mathrm{~s}, 1 \mathrm{H})$, 8.10-8.12 (d, $1 \mathrm{H}), 7.37-7.39(\mathrm{~d}, 1 \mathrm{H}), 5.25-5.28(\mathrm{~d}, 1 \mathrm{H}), 4.87-4.90(\mathrm{t}$, $2 \mathrm{H}), 4.49-4.53(\mathrm{~d}, 1 \mathrm{H}), 4.08-4.12(\mathrm{~d}, 1 \mathrm{H}), 3.04-3.11(\mathrm{~m}, 1 \mathrm{H}),, 2.84-2.94$ $(\mathrm{m}, 3 \mathrm{H}), 2.45-2.50(\mathrm{t}, 1 \mathrm{H}), 1.73(\mathrm{~m}, 5 \mathrm{H}), 1.53(\mathrm{~m}, 2 \mathrm{H}), 1.28(\mathrm{~m}, 3 \mathrm{H}) . \mathrm{IR}$ (KBr) cm-1: 2929,2855,1652,1524,1420,1345,896,784. MS:m/z 357.17

Synthesis of PZQ-3: PZQ-2 (0.36 g), ethanol ( $4 \mathrm{~mL})$, acetic acid $(4 \mathrm{~mL})$, Fe powder $(0.26 \mathrm{~g})$ and distilled water $(4 \mathrm{~mL})$ were added to a $100 \mathrm{~mL}$ three-neck flask, and finally a drop of concentrated $\mathrm{HCl}$ was added. The ensuing mixture was heated under reflux for $5 \mathrm{~h}$, the solvent was removed under reduced pressure. The water phase was extracted with $\mathrm{CH}_{2} \mathrm{Cl}_{2}(20 \mathrm{ML} \times 3)$. The combined organic layer was washed with aqueous sodium bicarbonate, distilled water and dried over anhydrous $\mathrm{Na} 2 \mathrm{SO} 4$, respectively. The solvent was removed under reduced pressure and the residue was subjected to column chromatography on silica gel. The product was separated with EA/PE(v/v, 9:1), yielding a slightly white solid. ${ }^{1} \mathrm{H}$ NMR $\left(\mathrm{CDCl}_{3}\right), \delta(\mathrm{ppm}): 7.00(\mathrm{~d}, 1 \mathrm{H}), 6.75(\mathrm{~s}, 1 \mathrm{H}), 6.70$ $(\mathrm{d}, 1 \mathrm{H}), 5.04(\mathrm{~d}, 1 \mathrm{H}), 4.70(\mathrm{~m}, 2 \mathrm{H}), 4.42(\mathrm{~d}, 1 \mathrm{H}), 4.05(\mathrm{~d}, 1 \mathrm{H}), 2.84(\mathrm{~m}$, $3 \mathrm{H}), 2.66(\mathrm{~d}, 1 \mathrm{H}), 2.46(\mathrm{~m}, 1 \mathrm{H}), 1.72(\mathrm{~m}, 5 \mathrm{H}), 1.52(\mathrm{~m}, 2 \mathrm{H}), 1.27(\mathrm{~m}$, 3H). IR (KBr) cm-1: 3352,2927,2854,1648,1509,1422,784,748. MS:m/z 327.19

Synthesis of PZQ-5: 4 was synthesized according to the literature.2019 Compound $4(0.099 \mathrm{~g})$ was dissolved in $\mathrm{CH} 2 \mathrm{Cl} 2(10 \mathrm{~mL})$ in a $50 \mathrm{~mL}$ three-neck flask. PZQ-3 (0.85 g), DCC (0.052 g) and HOBt $(0.034 \mathrm{~g})$ were added with stirring. The ensuing mixture was stirred for $10 \mathrm{~h}$ at room temperature. The solvent was removed under reduced pressure and the residue was subjected to column chromatography on silica gel. The product was separated with $\mathrm{EA} / \mathrm{CH}_{2} \mathrm{Cl}_{2}(\mathrm{v} / \mathrm{v}, 4: 1)$, yielding a yellow solid. ${ }^{1} \mathrm{HNMR}\left(\mathrm{CDCl}_{3}\right), \delta(\mathrm{ppm}): 8.58(\mathrm{~d}, 1 \mathrm{H}), 8.53$ $(\mathrm{d}, 1 \mathrm{H}), 8.43(\mathrm{~d}, 1 \mathrm{H}), 7.71(\mathrm{t}, 1 \mathrm{H}), 7.64(\mathrm{~s}, 1 \mathrm{H}), 7.26(\mathrm{~m}, 2 \mathrm{H}), 7.13(\mathrm{~d}$, $1 \mathrm{H})$, 5.05-4.07 (d, $1 \mathrm{H}), 4.76-4.48(\mathrm{t}, 2 \mathrm{H}), 4.42-4.46(\mathrm{~d}, 1 \mathrm{H}), 4.15-4.19$ $(\mathrm{d}, 2 \mathrm{H}), 4.42-4.44(\mathrm{~d}, 2 \mathrm{H}), 3.26-3.28(\mathrm{~d}, 2 \mathrm{H}), 2.89(\mathrm{~m}, 3 \mathrm{H}), 2.72-2.75(\mathrm{~d}$,
$1 \mathrm{H}), 2.40(\mathrm{~d}, 1 \mathrm{H}), 1.71-1.82(\mathrm{~m}, 13 \mathrm{H}), 1.52(\mathrm{~m}, 5 \mathrm{H}), 1.26(\mathrm{~m}, 5 \mathrm{H}), 0.85-$ $0.88(\mathrm{~m}, 3 \mathrm{H}) .13 \mathrm{C} \mathrm{NMR}\left(\mathrm{CDCl}_{3}\right), \delta(\mathrm{ppm}): 24.23,25.04,25.73,26.74$, 27.52, 28.40, 28.63, 36.54, 39.25, 40.14, 44.48, 48.41, 52.84, 54.25, 59.82, $66.36,114.41,115.99,116.42,119.02,122.61,125.27,125.49,129.13$, $129.24,129.54,130.61,132.00,132.53,136.69,155.10,163.41,163.85$, 166.11, 170.61, 171.24, 174.16. MS calcd. For: $\mathrm{C}_{41} \mathrm{H}_{47} \mathrm{~N}_{5} \mathrm{O}_{6}, 705.84$. Found: $728.4\left[\mathrm{M}^{+} \mathrm{Na}\right]^{+}$.

\section{Photophysical properties}

The UV-vis and fluorescence emission spectra of PZQ-5 in $\mathrm{CH}_{2} \mathrm{Cl}_{2}$ were studied, and fluorescence quantum yields of PZQ- 5 were determined using quinine sulfate as a standard (yield $=0.53$, in $0.1 \mathrm{M}$ $\mathrm{H}_{2} \mathrm{SO}_{4}$, $\lambda$ ex: $365 \mathrm{~nm}$ ).

\section{Cercaria imaging experiments}

Cercariaes were suspended in $200 \mu \mathrm{L} 5 \mu \mathrm{M}$ solution of PZQ-5 on a special plate for imaging. At last, fluorescence imaging of cercariae was observed by confocal microscopy at $1 \mathrm{~h}, 3 \mathrm{~h}$ and $4 \mathrm{~h}$, respectively.

\section{Results and Discussion}

\section{UV-vis and fluorescence emission spectra}

The photophysical properties of PZQ-5 were investigated before PZQ-5 was used to labeled cercariae. The UV-vis absorption and fluorescence emission spectra of PZQ-5 in a diluted solution of $\mathrm{CH} 2 \mathrm{Cl} 2$ were studied and are shown in Figure 1. Derivative PZQ-5 exhibits a broad UV-vis band and maximal absorbance at wavelengths of 400 $\mathrm{nm}$, corresponding to the $\pi-\pi^{*}$ transition of fluorophore [4]. Under excitation at $400 \mathrm{~nm}, \mathrm{PZQ}-5$ emits green fluorescence at a maximum wavelength of $510 \mathrm{~nm}$. The fluorescence quantum yield of PZQ-5 in water was measured to be 0.086 using quinine sulfate as a standard.

\section{Toxicity test}

In order to study their cytotoxicity, the MTT assay was used to detect cell survival rate of PZQ-5. The result of MTT can be seen in supporting information. Herein, no sub-cellular apoptotic changes or significant cell death was seen in cells after incubation with working concentrations for imaging. In general, PZQ-5 exhibits low cytotoxicity when used in a certain range of concentrations and within limited time periods of incubation.

\section{Cercaria imaging}

In view of its favorable spectroscopic properties, PZQ-5 should

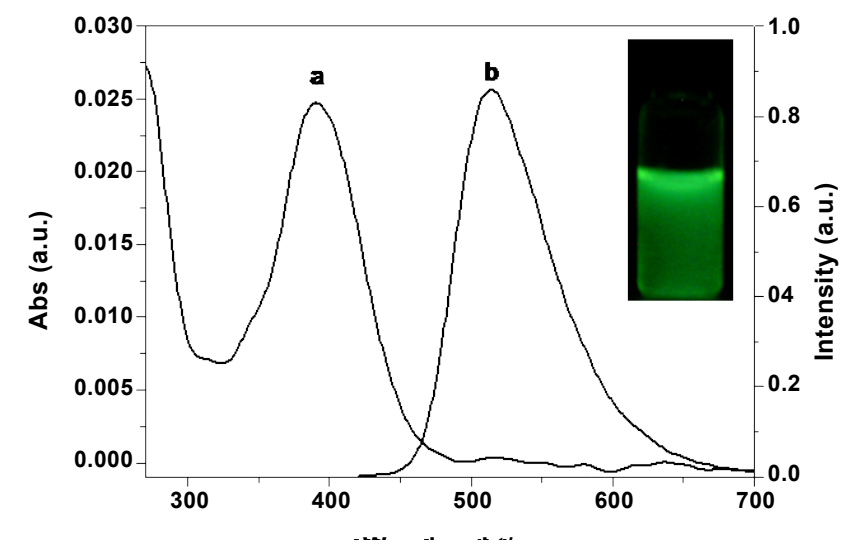

Figure 1: UV-vis absorption (a) and fluorescent emission spectra (b) of PZQ$5(10 \mathrm{mM})$ in $\mathrm{CH}_{2} \mathrm{Cl}_{2}$. 
be suitable for fluorescence imaging in living cells. The praziquantel derivative was used for labeling cercariae to observe the interaction between PZQ-5 with cercariae. The process of fresh cercariae labelled with PZQ-5 $(5 \mu \mathrm{M})$ was in-situ observed using confocal fluorescence microscopy, as shown Figure 2 The PZQ- 5 was taken up by cercariae through the tegument at $1 \mathrm{~h}$, but its fluorescence intensity was very low (Figure 2a). Then, fluorescence intensity in the cercarial tegument continually increased in the period from $2 \mathrm{~h}$ to $3 \mathrm{~h}$ (Figure $2 \mathrm{~b}$ and 2c). Even if the test time is extended, PZQ-5 is still mainly located at cercarial tegument.

From the reference mentioned [20] mentioned [21], the pharmacological effects of $C$. sinensis are cortex damage after praziquantel acting on them. It not only influences physiological function, but also affects some biochemical metabolism of $C$. sinensis. Pang H.L. group has reported the behavior of praziquantel acting on $C$. sinensis. $1 \mathrm{~h}$ after administration the glycogen content showed a slight decrease which became prominent $24 \mathrm{~h}$ later and almost disappeared at $48 \mathrm{~h}$ post-medication. There was an increase in protein content in the parenchymal tissues of worms $1 \mathrm{~h}$ after treatment, especially in the reproductive organ $24 \mathrm{~h}$ after treatment. RNA content was decreased $1 \mathrm{~h}$ post administration and continued decreasing gradually so that very little could be seen $48 \mathrm{~h}$ after. An increase in the aetivites of SDH, $\mathrm{MDH}$ and Ca-ATP was seen at the beginning and became marked $24 \mathrm{~h}$ after medication, while that for G-6-PDH was detected $48 \mathrm{~h}$ after drug administration [21].

From our results, no obvious fluorescence signal was detected in the initially one hour, but the test time is extended, more significant fluorescence signal appears in $2 \mathrm{~h}$, especially in the head and tail. Continue to extend the time to $3 \mathrm{~h}$, the fluorescence of cercariae tegument continued to increase. For the above-mentioned changes, we think that in $1 \mathrm{~h}$ the accumulation of drugs in tegument was less due to drug action time is short, so the fluorescence signal cannot be detected. With the increase of reaction time of drugs and cercariae, the drug in the cercariae tegument gathered more, the fluorescence signal also increased. Above all results, fluorescence signals mainly focus on the insects' epidermis, we could conclude that praziquante possibly mainly act on the cercarial tegument, thereby cause different morphology and

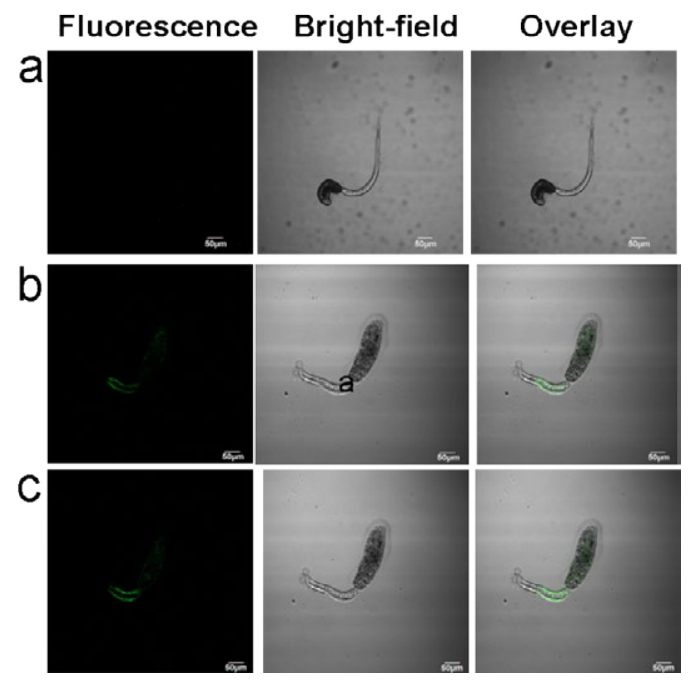

Figure 2: Confocal fluorescence, bright-field and overlay images of cercariae incubated with PZQ-5 (5 $\mu \mathrm{M})$ in PBS buffer at room temperature for $1 \mathrm{~h}(\mathrm{a}), 2 \mathrm{~h}$ (b) and $3 \mathrm{~h}$ (c). All excitation wavelengths are $405 \mathrm{~nm}$, and emission range was collected from 480 to $580 \mathrm{~nm}$. Scale bars $=50 \mu \mathrm{m}$. biological metabolism transforms. However, praziquantel have several influences to C. sinensis such as glycometabolism, ATP supersession and cholinesterase variation, we can't obtain same conclusions above here yet.

\section{Conclusion}

In summary, UV-vis and fluorescence emission spectra experiments proved that PZQ-5 have favorable spectroscopic properties. Fluorescence imaging experiments reveal that PZQ-5 is mainly located at cercarial tegument. It is concluded that the praziquantel can influent or demolish the cercarial tegument, which may lead to a series of change of morphology and biological metabolism for cercariae.

\section{Acknowledgment}

This work was supported by National Natural Science Foundation of China (Nos. 21303024, 21365003). The Jiangxi Provincial "Ganpo Talents 555 Projects" and Jiangxi Provincal Education Department Fund (KJLD13080, GJJ13664) are also gratefully acknowledged.

\section{References}

1. Lun ZR, Gasser RB, Lai DH, Li AX, Zhu XQ, et al. (2005) Clonorchiasis: a key foodborne zoonosis in China. Lancet Infect Dis 5: 31-41.

2. Kim DW, Kim JY, Moon JH, Kim KB, Kim TS, et al. (2010) Transcriptional induction of minichromosome maintenance protein $7(\mathrm{Mcm} 7)$ in human cholangiocarcinoma cells treated with Clonorchissinensis excretory-secretory products. Mol Biochem Parasitol 173: 10-16.

3. Choi D, Lim JH, Lee KT, Lee JK, Choi SH, et al. (2006) Cholangiocarcinoma and Clonorchissinensis infection: a case-control study in Korea. J Hepatol 44: 1066-1073.

4. Bouvard V, Baan R, Straif K, Grosse Y, Secretan B, et al. (2009) A review of human carcinogens--Part B: biological agents. Lancet Oncol 10: 321-322.

5. WHO, Foodborne trematode infections-Clonorchiasi.

6. Gnoula C, Guissou I, Dubois J, Duez P (2007) 5(6)-Carboxyfluorescein diacetate as an indicator of Caenorhabditis elegans viability for the development of an in vitro anthelmintic drug assay. Talanta 71: 1886-1892.

7. Keeney DB, Lagrue C, Bryan-Walker K, Khan N, Leung TL, et al. (2008) The use of fluorescent fatty acid analogs as labels in trematode experimental infections. Exp Parasitol 120: 15-20.

8. Weissleder R,Pittet MJ (2008) Imaging in the era of molecular oncology. Nature 452: 580-589.

9. Bringmann G, Gampe CM, Reichert Y, Bruhn T, Faber JH, et al. (2007) Synthesis and pharmacological evaluation of fluorescent and photoactivatable analogues of anti plasmodial naphthyl isoquinolines. J Med Chem 50: 61046115.

10. Shaner NC, Steinbach PA, Tsien RY (2005) A guide to choosing fluorescent proteins.Nat Methods 2: 905-909.

11. Pinaud F, Clarke S, Sittner A, Dahan M (2010) Probing cellular events, one quantum dot at a time. Nat Methods 7: 275-285.

12. Mengxiao Y, Qiang Z,Linxi S,Fuyou L, Zhiguo Z, et al. (2008) Cationic iridium(III) complexes for phosphorescence staining in the cytoplasm of living cells. Chem Commun 44: 2115-2117.

13. Frasco MF,Chaniotakis N (2010) Bioconjugated quantum dots as fluorescent probes for bioanalytical applications. Anal Bioanal Chem 396: 229-240.

14. Lippincott-Schwartz J, Patterson GH (2003) Development and use of fluorescent protein markers in living cells. Science 300: 87-91.

15. Zamir E, Lommerse PH, Kinkhabwala A, Grecco HE, Bastiaens PI (2010) Fluorescence fluctuations of quantum-dot sensors capture intracellular protein interaction dynamics. Nat Methods 7: 295-298.

16. Wang F, Liu X (2009) Recent advances in the chemistry of lanthanide-doped up conversion nanocrystals. Chem Soc Rev 38: 976-989.

17. Kohn AB, Lea JM, Moroz LL, Greenberg RM (2006) Schistosomamansoni: use of a fluorescent indicator to detect nitric oxide and related species in living parasites.ExpParasitol 113: 130-133.

18. Ronketti F, Ramana AV, Chao-Ming X, Pica-Mattoccia L, Cioli D, et al. (2007) 
Citation: Xie Y, Zheng L, Liu W, Wu Y, Li X, et al. (2014) Novel Fluorescent Derivative of Praziquantel Interaction with Clonorchis sinensis Cercariae. Med chem 4: 697-700. doi:10.4172/2161-0444.1000214

Praziquantel derivatives I: Modification of the aromatic ring.Bioorg Med Chem Lett 17: 4154-4157.

20. Wang HP (1997) zuozuo tong zhiliaohouhuazhizuo xi chongji li de yanjiu. Chin J Pub Heal 13: 344.

19. Xie Y, Li Y, Wu Y, Liu C, Li X, et al. (2013) Synthesis of fluorescent derivatives of praziquantel: cell-imaging and interaction with Schistosomajaponicumcercariae.

21. Pang XL, Li BZ, Yu XH (1990) Chin J Para Para Dis 8: 32 Org Biomol Chem 11: 5989-5993. 